\title{
EDITORIAL
}

\section{Chronic Fatigue Syndrome in Army General Practice}

A recent Editorial in the British Medical Journal (1) has cogently and succinctly stated what is currently known about Chronic Fatigue Syndrome (sometimes given the unhappy acronym 'ME', with its double implication of serious pathology in the nervous system 'Myalgic Encephalomyelitis' and of the suffering ego 'Me!' ).

The diagnosis is simply established by a history of disabling fatigue for more than six months with no obvious physical disease to explain it (2). Many with this complaint have a recognisable psychiatric condition but in others there is no ready explanation. Some may have had an infection, usually viral, but the relevance of this is uncertain and the studies purporting to show an important pathogenetic role for chronic viral infection have been, so far, unconvincing (3) .

No tests other than the history are needed to make the diagnosis; the definition of 'fatigue' is somewhat unsatisfactory and ambiguous but if taken to be the same as tiredness or lassitude it is one of the commonest presenting complaints in general practice (4).

Some doctors have established themselves as Chronic Fatigue Syndrome Specialists. There seems no reason however why most patients with this condition should not be treated entirely by their General Practitioners; no special training is needed to make the diagnosis and no investigations are required other than a full history and examination (and perhaps Full Blood Count, ESR, Urea and Electrolytes, Serum Calcium, Liver Function Tests, and TSH) to exclude other diseases.

Those sufferers who are clinically depressed or chronically anxious may require drug therapy or referral to a psychiatrist; in some cases the symptoms are clearly a response to an intolerable situation and appropriate advice must be given. Often the fatigue is entirely understandable, particularly in young women looking after several small children or those with demanding jobs and heavy domestic commitments. Some patients, fortunately a small minority, especially those who have made their own diagnosis and joined a 'self-help' group, seem to enjoy the status of 'ME Victims'; usually they have a devoted spouse who helps them to record their many symptoms and they may be reluctant to accept orthodox medical advice. Patience and understanding are required but these people often take themselves to different (medical and quasimedical) therapy centres; many do not get better but devote their lives to their disease.

The outlook for eventual improvement in people with disabling fatigue in general may not be good $(4,5)$. Unfortunately no reports have been published in the scientific literature of any effective curative treatment for Chronic Fatigue Syndrome. It logically follows that no 'Specialist' has anything better to offer at present than the patient's own General Practitioner who should know the sufferer better than anyone else. This doctor can reassure the patient that the symptoms are genuine, common, and not due to any life-threatening illness. Recovery with time is to be expected in many cases, and the GP should be able to provide reassurance, symptomatic treatment (other symptoms are manifold), and encouragement, when necessary.

Chronic Fatigue Syndrome has only recently been so named, but it is not new (6). 'Neurasthenia' was a popular disorder in the last century but went out of fashion when the physical explanation ('weakness of the nerves') ceased to be valid. During the First World War, when large numbers of men were unwillingly forced to undergo unpleasant and dangerous conditions in the trenches, 'Effort Syndrome' became a common diagnosis. This disease was characterised by chronic fatigue and a long list of other 'functional' symptoms which made those affected unfit for duty. It was thought to have some organic, possibly post-infective, basis initially, but was recognised in due course as largely a 'functional' and perhaps constitutional disorder. So many men became affected however, that the War Effort was put in danger. Special Rehabilita-g tion Hospitals were therefore set up and the sufferers were made to undergo staged physical training under medicat supervision. This regime was reasonably successful (considering that those who failed to respond were rewarded with a pension), with most patients able to return to some military occupation though only one third became fit for frontline duty (7). Preparations were afoot for a similar epidemic during the Second World War, but the disease was reclassified as 'anxiety neurosis' (8) and the expected cases did not materialise, perhaps because of the perceived pejorative nature of this diagnosis but maybe also because the conditions of service and the standards of fitness had improved.

Attitudes in the medical profession and indeed in the lay press at present are probably once again favourable for more of the chronically fatigued to present and be accepted as patients. There are undoubtedly significant numbers of such people in our community. We in the Army Medical Service still to some extent have at our disposal the treatment modality set up by our predecessors in 1915. Most Units have trained PT Instructors and it may be worth considering whether individual Service patients who have failed to respond to simpler measures as outlined above might benefit from a course of supervised physical training. The Medical Rehabilitation Units in England and Germany could be used for those who did not respond or were unsuitable for unit training. It should be possible also to arrange suitable fitness programmes for civilian patients in Army Practices. 
Army General Practitioners should be able to look after their patients with Chronic Fatigue Syndrome without the need to refer them to Service or other specialists and indeed may be better served with historically attested treatment facilities than their counterparts in civilian practice.

J H JOHNSTON

\section{REFERENCES}

1. Thomas P K. The chronic fatigue syndrome: what do we know? Br Med J 1993; 306: 1557-1558.

2. Sharpe M C, Archard L C, Banatvala J E, et al. A report - chronic fatigue syndrome: guidelines for research. J R Soc Med 1991; 84: 118-121.

3. P G Wallace. Epidemiology: a critical review. $\mathrm{Br}$ Med Bull 1991; 47: 942-951.

4. Kroenke K, Wood D R, Mangelsdorff A D, Meier $\mathrm{N}$, Powell $\mathrm{J}$ B. Chronic fatigue in primary care.
Prevalence, patients characteristics, and outcome JAMA 1988; 260: 929-934.

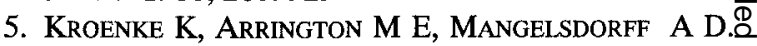
The prevalence of symptoms in medical outpatients and the adequacy of therapy. Arch Intern Med 1990, 150: $1685-1689$.

6. Abbey S E, Garfinkel P E. Neurasthenia and $\overrightarrow{\overline{\vec{s}}}$ chronic fatigue syndrome: the role of culture in theo making of a diagnosis. Am J Psychiatry 1991; 148: 1638-1646.

7. LewIS T. The Soldier's Heart and the Effort Syn- $\stackrel{\mathbb{D}}{\circ}$ drome. London: Shaw \& Sons, 1940.

8. Henderson D, Batchelor I R C. Psychoses and psy- $\overrightarrow{0}$ choneuroses in war. In: Henderson $\mathrm{D}$, Batchelor I RC. Henderson and Gillespie's Textbook of Psychia. try, Ninth Edition. London: Oxford University Press, 1962.

\section{ACADEMIC ACHIEVEMENTS}

\author{
FFOM \\ MD (Hong Kong) \\ MRCP (UK)
}

MRCPI

FRCA

MFPHM

MRCGP

Dip IMC RCS(Ed)
Colonel J R Brown, Late RAMC

Colonel I T Houghton, Late RAMC

Major I M McCurdie, RAMC

Capt J H Miller, RAMC

Captain P Connor, RAMC

Major C Barraclough, RAMC

Captain P J Sadler, RAMC

Colonel A H McG Macmillan, Late RAMC

Major M C M Bricknell, RAMC

Major J T Clark RAMC

Major D J Corps, RAMC

Major H A Cross, RAMC

Major J M Driscoll, RAMC

Major R W H Hooper, RAMC

Captain A McP Nicol, RAMC

Major R C Owers, RAMC

Major J J H Tuck, RAMC

Capt J H Miller, RAMC

Colonel R D George, Late RAMC

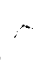

